\section{ACESSIBILIDADE NAS CORRIDAS DE RUA: BARREIRAS PERCEBIDAS PELAS PESSOAS COM DEFICIÊNCIA VISUAL}

\author{
ACCESSIBILITY IN STREET RACES: BARRIERS PERCEIVED BY PEOPLE WITH \\ VISUAL IMPAIRMENT
}

\section{ACCESIBILIDAD EN LAS CARRERAS DE CALLE: BARRERAS PERCIBIDAS POR LAS PERSONAS CON DISCAPACIDAD VISUAL}

\author{
Jéssica Dias Feliciano*, Michele Caroline de Souza Ribas*, \\ Vinícius Zeilmann Brasil*, Bruna Barboza Seron*
}

Palavras chave:

Transtornos de

visão.

Corrida.

Acessibilidade.

Mobilidade social.

Keywords

Vision disorders.

Running.

Accessibility.

Social Mobility.

Palabras clave:

Trastornos de la

visión.

Carrera.

Accesibilidad.

Movilidad social.
Resumo: 0 objetivo deste estudo foi identificar as barreiras percebidas pelas pessoas com deficiência visual para a prática da corrida de rua. Participaram da pesquisa sete indivíduos com deficiência visual residentes de Florianópolis, com idades entre 22 e 54 anos. Foi realizada uma entrevista semiestruturada, objetivando levantar informações sobre as barreiras para a prática esportiva. Por meio dos relatos foram observadas barreiras urbanísticas relacionadas ao terreno e obstáculos e barreiras específicas do esporte por questões de insegurança em virtude da falta de acessibilidade e em relação ao guia e à desigualdade de participação nas competições. Também foram mencionadas barreiras de comunicação e informação, atitudinais, tecnológicas e arquitetônicas. Notase que pessoas com deficiência visual enfrentam inúmeras barreiras para a prática da corrida de rua, dificultando sua manutenção. 0 estudo propõe possibilidades de soluções aos problemas encontrados, diminuindo, significativamente, as principais barreiras e contribuindo para uma prática segura e igualitária.

\begin{abstract}
This study aimed at identifying the barriers perceived by people with visual impairment to practice street racing. Participants were seven 22-54-year-old visually impaired residents from Florianópolis. A semi-structured interview was conducted to gather information about the barriers to sports practice. Their accounts pointed to city planning barriers related to the terrain as well as obstacles and barriers specific to sport related to insecurity due to lack of accessibility, guides and unequal participation in competitions. They also mentioned communication and information, attitudinal, technological and architectural barriers. People with visual impairment face numerous barriers to practice street racing, making it difficult to maintain it. The study proposes possible solutions to the problems found, significantly reducing the main barriers and contributing to safe and egalitarian practice.
\end{abstract}

Resumen: El objetivo de este estudio fue identificar las barreras percibidas por las personas con discapacidad visual para la práctica de carreras de calle. Participaron en la investigación siete individuos con discapacidad visual, residentes de Florianópolis, con edades entre 22 y 54 años. Se realizó una entrevista semiestructurada con el objetivo de obtener informaciones sobre las barreras para la práctica deportiva. A través de los relatos se observaron barreras urbanísticas relacionadas al terreno y obstáculos y barreras específicas del deporte por cuestiones de inseguridad debido a la falta de accesibilidad y en relación al guía y a la desigualdad de participación en las competiciones. También se mencionaron barreras de comunicación e información, actitudinales, tecnológicas y arquitectónicas. Es notorio que personas con deficiencia visual enfrentan innumerables barreras en la práctica de carreras de calle, dificultando mantenerlas. El estudio propone posibilidades de soluciones a los problemas encontrados, disminuyendo, significativamente, las principales barreras y contribuyendo para una práctica segura e igualitaria.
*Universidade Federal de Santa Catarina. Florianópolis, SC, Brasil. E-mail: jeeufsc@gmail.com; souza.michele@ufsc.br; vzbrasil@ hotmail.com; bruna.seron@ufsc.br

Recebido em: 24-04-2019 Aprovado em: 20-10-2019 Publicado em: 21-12-2019

DOI https://doi.org/10.22456/1982-8918.92172 (c) (i) (2) Licence 


\section{INTRODUÇÃOO}

O estado de saúde e bem-estar de pessoas com deficiência é determinante para sua capacidade de socialização, aprendizagem, trabalho e autonomia (GREGUOL, 2017). Pensar em políticas públicas que ofereçam acesso a serviços para essa população é indispensável, pois, segundo o último Censo, 23,9\% da população tem alguma deficiência (IBGE, 2012). A deficiência visual (DV) figura como a mais representativa, sendo o Sul do Brasil a região que apresentou esse indicador mais elevado (IBGE, 2015).

O Relatório Mundial sobre a Deficiência (RELATÓRIO..., 2012) destaca que as pessoas com DV apresentam uma taxa de saúde precária. Além das condições desiguais vivenciadas pelas pessoas com deficiência, aquelas que têm DV enfrentam dificuldades para desempenhar atividades habituais, tais como pegar ônibus e deslocar-se (IBGE, 2015). Prejuízos em atividades cotidianas influenciam diretamente a adesão e aderência de outras tarefas que envolvam a adoção de hábitos saudáveis. Com a minimização dos impedimentos, haveria uma melhora significativa em condições secundárias e em aspectos psicossociais, contribuindo com a autonomia e independência dos indivíduos, e uma consequente diminuição de gastos com a saúde para essa população (LIMA; GORGATTI; DUTRA, 2010, SERON; ARRUDA; GREGUOL, 2015). Logo, são evidentes os benefícios que a adoção de hábitos saudáveis pode trazer para a vida dessas pessoas, se adequações cabíveis e necessárias por conta das desigualdades frente às pessoas com deficiência forem concretizadas.

A prática de atividades físicas figura como um hábito saudável, no entanto, pessoas com deficiência têm menos oportunidades de participar de programas de atividade física e apresentam menores níveis de aptidão física (CERVANTES; PORRETA, 2010). Rangel e Farias (2016) relatam que muitas das características importantes para uma vida saudável podem ser alcançadas com a prática da corrida, sobretudo, pelas adaptações fisiológicas proporcionadas pela modalidade. Embora a corrida envolva baixo custo e facilidade de sua prática, para as pessoas com cegueira, as barreiras para essa prática apresentam-se constantemente, por exemplo, pela necessidade de um guia.

As barreiras são caracterizadas, segundo a Lei Brasileira de Inclusão da Pessoa com Deficiência, por qualquer entrave, obstáculo, atitude ou comportamento limitante ou que impeça a participação social da pessoa, assim como o gozo, o usufruto e o exercício de seus direitos à acessibilidade, à liberdade de movimento e de expressão. Nessa lei, as barreiras são classificadas como: urbanísticas, arquitetônicas, nos transportes, comunicacionais e na informação; atitudinais e tecnológicas (BRASIL, 2015). No entanto, quando se trata de estudos de prática de atividades físicas e/ou esportivas, as barreiras são comumente apresentadas como pessoais ou ambientais.

Apesar da escassez de pesquisas que identificam barreiras para a prática de atividade física de pessoas com DV, um estudo de Jaarsma et al. (2014) envolvendo indivíduos com DV ativos e inativos verificou que as barreiras pessoais foram as mais frequentemente reladas, sendo a dependência de outra pessoa para os fisicamente ativos e a própria deficiência visual para os inativos.

A corrida de rua deveria, também, ser acessível às pessoas com DV, mediante a relevância da prática esportiva para o desenvolvimento de hábitos saudáveis. Portanto, verificar quais são os impedimentos que dificultam essa prática pode auxiliar no desenvolvimento de 
soluções por parte dos envolvidos com este ambiente e na proposição de criação de políticas públicas que garantam o acesso ao lazer e ao esporte, previsto em lei. Diante do exposto, este estudo teve como objetivo identificar as barreiras percebidas pelas pessoas com DV para a prática da corrida de rua.

\section{MÉTODOS}

\subsection{PARTICIPANTES}

Participaram do estudo sete pessoas com DV (três mulheres). Todos os indivíduos entrevistados faziam parte do Projeto Sexto Sentido, realizado na cidade de Florianópolis/SC, que viabiliza o esporte como ferramenta de inclusão. A escolha dos participantes ocorreu pela manifestação de interesse e disponibilidade em participar da pesquisa, bem como de realizar treinos nas ruas e participar de competições no mesmo âmbito.

\subsection{INSTRUMENTOS E PROCEDIMENTOS PARA COLETAS DE DADOS}

O maior número possível de pessoas com DV praticantes de corrida de rua foi contatado mediante redes sociais, telefone e conversas presenciais com os integrantes do Projeto Sexto Sentido. Por se tratar de pessoas com DV, optou-se pelo envio eletrônico do Termo de Consentimento Livre e Esclarecido, devido aos recursos de acessibilidade tecnológicos existentes.

Como instrumento de pesquisa foi utilizado um roteiro de entrevista semiestruturado, com questões fechadas e abertas. As questões fechadas caracterizavam os participantes da pesquisa, já as abertas foram compostas por perguntas referentes à percepção sobre as barreiras enfrentadas pelos participantes para realizarem treinos e competições no âmbito das corridas de rua. O repertório abrangeu perguntas que contemplaram aspectos da corrida, da chegada e da volta, tanto em dias de treino, como em competição. As indagações foram feitas com base na Lei Brasileira de Inclusão da Pessoa com Deficiência no 13.146, de 6 de julho de 2015.

Com a autorização dos participantes, a entrevista foi gravada com aparelho digital, da marca Sony, modelo Icd-Px 240, para serem analisadas posteriormente. Após a entrevista, foram requisitadas mais informações, mediante contato por meios eletrônicos. Optou-se por esse método de obtenção de dados por permitir maior profundidade e clareza na explanação da percepção dos participantes.

Todas as entrevistas transcritas foram comparadas com os respectivos áudios. Posteriormente, a transcrição foi enviada aos participantes para que eles pudessem realizar modificações que julgassem necessárias, antes de ser feita a análise de conteúdo.

\subsection{ANÁLISE DOS DADOS}

Em todas as entrevistas houve o emprego de códigos quanto ao nome dos participantes e aqueles que eram citados por eles, garantindo o sigilo dos envolvidos. A denominação empregada foi $\mathrm{C}$, que se refere a corredor e o número de acordo com a ordem alfabética dos sujeitos participantes do estudo. 
Para a análise dos dados, foi utilizada a técnica de análise de conteúdo, através do método de análise por categorias temáticas, em que a fala de cada participante é encaixada em alguma das categorias previamente estipuladas (CAREGNATO; MUTTI, 2006). Neste estudo, as análises obedeceram as seguintes fases: (1) Pré-exploração do material ou de leituras flutuantes, em que foram captados aspectos importantes para as próximas fases; (2) Seleção das unidades de análise, ou seja, seleção de sentenças de acordo com o tema; e (3) Processo de categorização e subcategorização (BARDIN, 2009).

Essas etapas foram realizadas de forma individual e posteriormente as falas dos participantes foram agrupadas nos respectivos quadros referentes às categorias de barreiras previamente estipuladas. Porém, como se trata de um estudo no contexto esportivo, houve a necessidade da criação de outra categoria de barreiras, denominada de "específicas do esporte", pois as barreiras encontradas e alocadas nesta categoria não se encaixavam nas existentes. Dentro desta categoria, foram distribuídas outras três subcategorias: Pessoais, Organizacionais e Recursos Humanos. Todas essas subcategorias foram criadas a partir das barreiras citadas nos estudos de Alves e Duarte (2005), Scelza et al. (2005), Shields, Synnot e Barr (2012), Souza e Bruel (2012), Cordeiro (2016).

Depois da criação de novas categorias, designou-se um novo quadro ao lado dos recortes de falas com a finalidade de extrair exatamente a barreira que estava sendo exposta pelo corredor. Caso mais de uma pessoa citasse a mesma barreira, seu código era colocado ao lado. Por fim, foram contadas todas as barreiras citadas pelos corredores para expor a quantidade de barreiras percebidas por este grupo.

\section{RESULTADOS}

No momento de realização do estudo todos os participantes residiam no município de Florianópolis e/ou Grande Florianópolis. Na Tabela 1 estão apresentados alguns indicadores sociodemográficos que caracterizam os corredores entrevistados.

Tabela 1 - Características sociodemográficas dos corredores de rua com deficiência visual.

\begin{tabular}{|c|c|c|c|c|c|c|}
\hline C & Sexo & Idade $^{*}$ & TPCR $^{*}$ & TD & Classificação & Escolaridade \\
\hline $\mathrm{C} 1$ & M & 29 & 3 & Congênita & $\begin{array}{c}\text { Baixa visão } \\
\text { B2/T12 }\end{array}$ & Ensino médio completo \\
\hline C2 & $\mathrm{F}$ & 22 & 3 & Congênita & $\begin{array}{c}\text { Baixa visão } \\
\text { B2/T12 }\end{array}$ & Superior em andamento \\
\hline C3 & M & 46 & 8 & Adquirida & $\begin{array}{c}\text { Cegueira } \\
\text { B1/T11 }\end{array}$ & Superior completo \\
\hline C4 & $\mathrm{F}$ & 31 & 9 & Adquirida & $\begin{array}{l}\text { Cegueira } \\
\text { B1/T11 }\end{array}$ & Superior completo \\
\hline C5 & M & 54 & 4 & Adquirida & $\begin{array}{c}\text { Cegueira } \\
\text { B1/T11 }\end{array}$ & Superior completo \\
\hline C6 & $\mathrm{F}$ & 37 & 5 & Congênita & $\begin{array}{l}\text { Cegueira } \\
\text { B1/T11 }\end{array}$ & Superior completo \\
\hline $\mathrm{C} 7$ & M & 49 & 2 & Adquirida & $\begin{array}{l}\text { Cegueira } \\
\text { B1/T11 }\end{array}$ & Pós-graduação completo \\
\hline
\end{tabular}

Fonte: Elaborado pelos autores. 
Conforme as declarações dos corredores investigados, verificou-se uma variedade de barreiras para a prática da corrida de rua. Considerando a frequência com que foram mencionadas entres os participantes, apresentou-se: barreiras urbanísticas (7), as específicas do esporte (7), as atitudinais (5), as comunicacionais (4) e as de transportes (1). Tais barreiras, no caso desses indivíduos, perpassam as situações cotidianas ligadas aos treinamentos e às competições de corridas de rua.

As barreiras urbanísticas corresponderam àquelas mencionadas por alguns corredores investigados (7). As características e o estado de conservação das vias de acesso e dos locais frequentados pelos corredores para a prática da corrida de rua foram destacados por esses indivíduos. O corredor C3 destaca que: "[...] os percursos, as calçadas, para gente, sempre são desgastantes. Você coloca o pé para fora da casa, já começa o desafio, já começa a superação, às vezes você tem que ir pela rua [...]" (C3).

De modo semelhante, o corredor $\mathrm{C} 1$ menciona as dificuldades encontradas por ele para se deslocar por meio das calçadas: "[...] eu tenho que andar mais na rua do que na calçada, porque a calçada não é muito boa, não... tem alguns buracos, e é uma calçada meio estreita e aí é melhor ir no asfalto mesmo [...]" (C1). Ao relatar uma situação de seu cotidiano, o corredor C7 indica outras barreiras que comprometem sua autonomia para 0 acesso aos locais de treino:

[...] por exemplo, quando se treina na beira mar norte... são lugares que eu realmente não tenho segurança para fazê-lo sozinho... Em função dessa falta de acessibilidade, o trânsito, é complicado, são muitas vias, em vários sentidos, e, não existem sinais sonoros nestas vias, é, são vias rápidas e isso gera bastante insegurança. (C7)

As barreiras urbanísticas em situações de competição, mencionadas $\mathrm{C} 2$ e C4, recaem sobre as condições e características do terreno onde a prova é realizada. $\mathrm{O}$ corredor $\mathrm{C} 4$ destaca que: "[...] o percurso tem muita subida, muita descida, degrau, buraco, calçada... isso tudo também é dificuldade [...]" (C4).

A respeito das barreiras específicas do esporte (7), nesse caso o contexto no qual a prática da corrida de rua ocorre em situações de treinamento e competição, verificou-se um consenso entre alguns corredores sobre a insegurança que têm referente à competência de seu guia, o que fica evidente na declaração do corredor C4:

[...] quando muda o guia é uma dificuldade, porque às vezes a gente não sabe se o guia está preparado ou não, claro que todos que entram acabam conhecendo um pouco da vida do deficiente e têm um preparo para saber como lidar com o deficiente... no meu caso, eu sou bem realista em falar que eu não confio no primeiro momento, o guia tem que me passar segurança para dizer assim: vamos que agora eu tô bem! (C4).

Algumas circunstâncias específicas das situações em que participam de competições foram mencionadas pelos corredores C3, C4 e C6. No caso particular de C4 ele destaca a dificuldade encontrada diante da estrutura disponibilizada aos corredores durante as competições:

[...] a estrutura do banheiro, muito pequeno, a hora que tu vai sentar tu já bate quase com o rosto na porta, tu fica se movimentando ali dentro para localizar o vaso, porque daí tu tem que fechar a porta, às vezes tem as moças que tão cuidando do lado de fora, mas às vezes acontece de elas irem em outro banheiro, e você usar ali sozinha, então, tu tem que fechar, porque se não vem um, abre a porta... (C4). 
A estrutura e a organização das provas, para os corredores C3 e C6, geralmente, não valorizam a participação dos atletas com deficiências visuais. C6 recorda que: "[...] quando a gente acaba não conseguindo sair na frente, a gente acaba pegando um pouco do tumulto, daí tu não consegue colocar um ritmo melhor [...]" (C6). Para C3, o que a competição oferece em termos de organização e premiação parece ser uma forma de valorização das pessoas com deficiência, como ele mesmo explica:

[...] algumas provas, por exemplo, no início, não ofereciam premiação, hoje a gente já tem algumas provas que eles têm a categoria das pessoas com deficiência, inclusive existe troféus de $1^{\circ}, 2^{\circ}, 3^{\circ}$ lugar, masculino, feminino... já fui em provas que até premiação nos deram, outras que não... (C3)

As barreiras atitudinais mencionadas pelos corredores com deficiência visual (5) estão presentes, predominantemente, em situações de competições. A falta de conhecimento dos atletas participantes e dos próprios organizadores das provas parece desconsiderar as condições, necessidades e limitações dos corredores com deficiência visual, evidenciado em detalhes na declaração de C7:

[...] eu percebo uma exposição muito grande. Primeiro, porque os locutores não usam termos adequados para se referirem às pessoas com deficiência, então a gente ouve de tudo, em alguns momentos chega a ser até constrangedor... Ah, falam em deficiência física como se todas as deficiências fossem físicas... se for para usar, que usasse terminologias adequadas. Eu escuto muitos comentários piedosos, cria uma atmosfera sensacionalista em torno dos acontecimentos, e é uma coisa que eu realmente não curto, não gosto... (C7)

A partir das declarações do corredor C4 é possível verificar atitudes, dos próprios atletas, em circunstâncias específicas de competição que desconsidera a condição física dos corredores com deficiência visual, como ele mesmo relata no excerto abaixo:

[...] eu tive participando de uma competição com uma moça que me guiou e eles pediram para que os deficientes largassem na frente, e na hora da largada eles não respeitaram o momento da nossa saída, saíram todos juntos e eles saíram empurrando a gente, como se a gente tivesse enxergando... (C4)

Em relação às barreiras comunicacionais enfrentadas pelos corredores (4), averiguouse que, nas situações de deslocamento para o local dos treinos, conseguir chegar ao local de destino, com autonomia, é inviável pela falta de sinalização. O corredor C6 destaca que: "[...] eu não costumo ir por ali, não conheço exatamente o caminho, chega um determinado ponto que eu fico toda confusa, não sei se eu vou para esquerda ou para direita [...]" (C6).

Nas situações de treinamento, particularmente, os corredores C4 e C7 mencionaram a dificuldade de comunicação e de receberem informações de seus treinadores. Estes corredores mencionam a existência de uma ferramenta/aplicativo específico para obterem dados sobre 0 seu desempenho nos treinos, conforme explica C7: "[...] o pessoal usa bastante um aplicativo para dizer se tu fez ou não o treino, então, nem sempre esses aplicativos estão acessíveis para que a gente possa preencher todos os dados adequadamente [...]" (C7). De fato, por meio desse recurso tecnológico os corredores podem ter acesso aos feedbacks do treinador.

Em situações de competições, o corredor C2 recorda um episódio em que: "[...] os staffs faziam sinais, só que eu não conseguia enxergar os sinais que eles faziam, se eles falassem: para direita, para esquerda! Eu iria me localizar melhor [...]" (C2). Nesse mesmo contexto, C7 discorre sobre uma situação fundamental para que possa participar das competições: "[...] nem 
sempre é possível a gente fazer a inscrição em função da falta de acessibilidade nos sites, então a gente tem sempre que pedir para alguém, passar dados pessoais, enfim [...]" (C7).

No que diz respeito às barreiras nos transportes, o corredor C2 relata uma situação cotidiana de deslocamento ao local dos treinamentos: "Para pegar o ônibus, eu peço ajuda porque eu não consigo ler o letreiro... daí eu fico perguntando qual ônibus que é... daí eu explico que eu tenho baixa visão e não consigo enxergar o letreiro [...]" (C2).

\section{DISCUSSÃO}

A presente pesquisa teve como objetivo a identificação das barreiras para a prática da corrida de rua por atletas com DV. Dentre as barreiras identificadas, as que foram apontadas com mais frequência foram as urbanísticas e as específicas do esporte.

Nas barreiras urbanísticas, os participantes indicam que há dificuldade em atravessar a rua, que há muitos obstáculos e que os locais existentes são impróprios para treino, tanto pelo próprio terreno, quanto pela quantidade de pessoas circulando. A lei complementar no 482 de 17 de janeiro de 2014 institui o plano diretor do município de Florianópolis, e visa à organização do território municipal de forma a promover qualidade de vida, interação social e o bem-estar da população (FLORIANÓPOLIS, 2014). Uma das formas de alcance da qualidade de vida para algumas pessoas é por meio da prática esportiva (LIMA; GORGATTI; DUTRA, 2010). Porém, para ter acesso aos locais destinado para "todos", algumas pessoas com deficiência enfrentam dificuldades. Apesar de muitas vezes as barreiras apontadas também serem obstáculo para qualquer pessoa, nota-se que para pessoas com deficiência é mais acentuado.

Kirchner, Gerber e Smith (2008) investigaram barreiras comunitárias para a prática de atividade física, percebidas por 134 pessoas de Nova York, com deficiência motora e visual. Foram relatados, pelos participantes, problemas com pavimentação de calçadas, calçadas estreitas e multidões, semelhantemente ao presente estudo. Os autores ainda relatam que essas pessoas alteram as suas rotas ou se deslocam mais devagar do que o planejado, devido aos problemas encontrados, sendo esta uma das tarefas constantes dos corredores com DV.

O planejamento de espaços urbanos requer compreensão acerca das barreiras específicas enfrentadas pelas pessoas com diferentes tipos de deficiência, para que, assim, o município possa melhor atendê-las. O estudo cauteloso e respeitando as normas de acessibilidade diminuirá, ou até mesmo sanará, os problemas de pessoas com deficiência visual, motora e até mesmo com mobilidade reduzida.

Nas barreiras urbanísticas do presente trabalho, a grande circulação de pessoas foi apontada como um dos fatores limitantes para a prática esportiva; esse fator está diretamente relacionado com a falta de um lugar adequado, pois pessoas com cegueira e algumas com baixa visão necessitam de um guia ao seu lado (SOUZA; BRUEL, 2012), o que resulta em uma ocupação maior do espaço e, consequentemente, maior dificuldade de deslocamento em espaços demasiadamente procurados.

As dificuldades encontradas no deslocamento foram fortemente mencionadas pelos participantes, sendo apontada como barreira a travessia das ruas e avenidas, em virtude da falta de sinalização sonora nestes ambientes. Novamente, dentro do plano diretor do município de Florianópolis, encontra-se a exigência da construção e implementação de semáforos acionados 
(FLORIANÓPOLIS, 2014). Contudo, em se tratando das pessoas com DV, e relembrando as necessidades relativas à deficiência sensorial, apenas a utilização de semáforos sonoros sanariam este problema, como os próprios entrevistados relatam.

As barreiras pessoais percebidas pelas pessoas com DV referem-se à insegurança gerada pelo guia, por não ter ciência quanto ao seu conhecimento e a insegurança gerada pela falta de acessibilidade. A ausência de companhia, guia, é apontada também como barreira para a prática de atividade física em outros estudos (CORDEIRO, 2016; JESUS; JESUS, 2012). Com a proposta de sanar esses problemas, e em virtude da carência de atletas guias, o Centro de Referência, Qualidade de vida e Movimento (CRQVM), de Curitiba, realizou um curso de capacitação para fomentar a participação das pessoas com DV nas corridas de rua promovidas pela prefeitura, bem como a preocupação com a inserção social. Além disso, os participantes foram cadastrados, para que a pessoa com deficiência pudesse fazer essa busca (CURITIBA, 2013). Outra observação seria o fato de levar ao conhecimento da população algumas necessidades particulares das pessoas com DV e, assim, tornar a população mais consciente de seus atos e torná-los capazes de propagar as informações recebidas.

Quanto às barreiras específicas do esporte, na sua subcategoria de organização dos eventos esportivos, resultados como a falta de estrutura dentro do ambiente de competição, restrições na participação, falta de largada diferenciada e até mesmo tentativa de barrar inscrições se mostraram de forma bastante expressiva na fala dos entrevistados. Recentemente, foi criado o Projeto de Lei n_6.860 de 2017, que dispõe sobre a acessibilidade a eventos realizados ao ar livre, alterando as leis vigentes (BRASIL, 2017). Devido à falta de clareza nas leis em vigor, foi acrescido o parágrafo $3^{\circ}$ ao artigo 42 da lei $n^{\circ} 13.146$ de 6 de julho de 2015, garantindo 0 acesso aos eventos culturais e esportivos realizados ao ar livre, promovidos pelo poder público e/ou por agentes privados. Além deste incremento, foi acrescido um inciso ao artigo 60 da mesma lei, que aponta o planejamento dos elementos de urbanização públicos e privados de uso coletivo, incluindo as instalações provisórias comumente utilizadas em eventos esportivos ao ar livre. Já na lei n- 10.098 de 2000, houve o acréscimo do artigo 24-A, que relata que as disposições impostas na lei são aplicáveis, também, às instalações provisórias de eventos culturais ou esportivos, realizados ao ar livre, sob a promoção do poder público e agentes privados. A proposta foi aprovada pela Comissão de Desenvolvimento Urbano e aguarda as comissões de Defesa dos Direitos das Pessoas com Deficiência e Constituição e Justiça e de Cidadania.

Segundo as normas para participação de atletas com deficiência em corridas de rua emitidas pelo CPB (CPB, [2019]), para os atletas com DV que competem com guia, o uso de um colete na cor laranja deve ser fornecido ao guia, pela organização da prova para identificálo. Os atletas devem ser alocados em um pelotão diferenciado para que não haja prejuízo na performance.

As barreiras atitudinais são vistas por Newton e Araújo (2016) como a raiz de todas as outras, pois é a exclusão que constitui inúmeros fatores impeditivos da efetiva integração das pessoas com deficiência no meio urbano, e reflete no resultado encontrado, pois houve relatos de atropelamentos na ciclovia, já que não há um lugar adequado para que os praticantes da corrida possam realizá-la de forma segura. Ou seja, uma barreira está vinculada a outra.

Um estudo envolvendo pessoas com deficiência e sem deficiência teve como objetivo realizar uma reflexão acerca da percepção e entendimento que essas pessoas tinham sobre as 
barreiras atitudinais (PONTE; SILVA, 2015). Como resultado, foram encontrados apontamentos semelhantes aos apresentados neste trabalho. As pessoas com deficiência apontaram que os carros estacionados em locais impróprios são barreiras. Além disso, a falta de respeito frente às faixas de segurança foi relatada, diferentemente do presente estudo, onde foi apontado no contexto esportivo, o desrespeito à largada diferenciada, e não no cotidiano. Por fim, a falta de conhecimento foi outro ponto em comum de ambas as investigações, sendo relacionada à deficiência ou às habilidades do sujeito.

Como solução para o problema atitudinal, Ponte e Silva (2015) afirmam que a promoção de informações possibilita que haja a participação das pessoas com deficiência nas diversas atividades sociais, sem se deparar com o preconceito e as barreiras. Ainda no estudo supracitado, os autores apontam as barreiras nos transportes como as mais citadas, na presente pesquisa, esta barreira foi uma das menos citadas, e também encontra-se relacionada com a barreira comunicacional.

Nas barreiras comunicacionais e na informação, os participantes apontaram como obstáculos a má sinalização presente nas competições, a falta de informações para pegar ônibus, pois os letreiros não são acessíveis e, por fim, as dificuldades de comunicação geradas pelas tecnologias. Nesse sentido, a Associação Brasileira de Normas Técnicas (ABNT) tem diretrizes referentes à acessibilidade em veículos de características urbanas para o transporte coletivo de passageiros, intitulada NBR 14022 (ABNT, 2011). No tópico 7, subitem 7.1.2, é mencionado que nos pontos de parada e/ou plataformas deve conter sinalização visual, tátil e auditiva, com informações pertinentes aos itinerários. Porém, como exposto nos resultados, o tipo de comunicação existente não abrange todos os indivíduos, visto que, muitas vezes, as letras são pequenas e os letreiros ficam altos. Apesar de não estar previsto na norma a forma como a comunicação visual deve ser feita, os recursos de letras ampliadas poderiam ser suficientes para a população com baixa visão. Já para aqueles que têm cegueira, a sinalização tátil, em braille, poderia ser um recurso.

Nas barreiras comunicacionais, outra categoria de barreiras está inclusa na fala do participante, quando explica que o celular não está bem adaptado, gerando comprometimento na comunicação com o treinador. As dificuldades encontradas para utilizar aparelhos telefônicos também foram relatadas no estudo de Braga et al. (2012), porém, os participantes compararam marcas dos seus equipamentos e relataram que a Apple é um exemplo de acessibilidade. Um estudo abordando o tema da acessibilidade afirma que esse obstáculo é encontrado em virtude do elevado custo das ferramentas de acessibilidade tecnológicas (softwares), além disso, que o aparelho deve comportar a instalação (REINALDI; CAMARGO JÚNIOR; CALAZANS, 2011). O estudo feito por Reinaldi, Camargo Júnior e Calazans (2011) mostra que, apesar das ferramentas existentes apresentarem facilidade na utilização de equipamentos tecnológicos, ainda existem fatores que dificultam a concretização desta ação. A falta de padronização na construção de páginas da web acarreta o comprometimento da leitura eficiente das informações. Além disso, houve relatos de que as ferramentas nem sempre são capazes de ler os programas ou gráficos.

Apesar de esta pesquisa ser de grande relevância e utilidade para diversas finalidades, por estar ouvindo aqueles que de fato vivenciam as situações descritas até então, o presente estudo não está ausente de limitações. Nomeadamente, o número reduzido de pessoas com deficiência visual apresentado no estudo e o pertencimento a um mesmo grupo podem limitar 
os resultados, pois possivelmente a trajetória de treinos e competições seja a mesma, sendo interessante explorar corredores com deficiência visual de diferentes municípios e até grupos.

\section{CONSIDERAÇÕES FINAIS}

As políticas públicas com campanhas informativas e a adequação dos espaços relacionados à prática esportiva e ao cotidiano da pessoa com deficiência são necessárias para que haja a oportunidade de desfrutar de uma vida sem barreiras e com maior situação de igualdade. A disseminação de conhecimento referente ao tema permite que ocorra maior abrangência em diferentes esferas e que, assim, estratégias que facilitem a prática esportiva pelas pessoas com deficiência sejam adotadas por todos.

No que concerne às aplicações práticas, o estudo apresenta, nos quadros a seguir, alguns facilitadores direcionados, com o objetivo de que algumas medidas simples, porém importantes, possam ser mais bem visualizadas e implementadas.

\section{Quadro 1 - Direcionamentos práticos para o município}

- Criar políticas públicas informativas sobre deficiência visual;

- Realizar treinamento de pessoas para serem guias de corrida;

- Implementar semáforos sonoros;

- Melhorar a acessibilidade urbanística em geral em respeito às normas ABNT;

- Fomentar a prática esportiva para pessoas com deficiência;

- Oferecer ambientes adequados para serem realizados treinos;

- Adequar os sistemas e meios de transporte, de acordo com as normas ABNT.

Fonte: Elaborado pelos autores.

Quadro 2 - Direcionamentos práticos para organizações de eventos esportivos ao ar livre

- Proporcionar acessibilidade dentro dos ambientes da competição;

- Disponibilizar banheiros móveis adaptados;

- Oferecer colete de identificação para guias;

- Incluir categoria de Pessoa com Deficiência;

- Oferecer premiação em igualdade;

- Oferecer sinalização nos percursos em cores contrastantes e/ou sonora;

- Utilizar sites que sejam acessíveis;

- Oferecer largada diferenciada (3 minutos de antecedência);

- Utilizar termos adequados para se referir às pessoas com deficiência.

Fonte: Elaborado pelos autores.

Quadro 3 - Direcionamentos práticos para guias de corrida

- Estar, sentir-se e mostrar-se preparado para guiar alguém;

- Não superproteger a pessoa que está guiando;

- Sanar as dúvidas;

- Perguntar a melhor forma de guiá-lo, quanto ao lado e forma de segurar a guia;

- Saber o ritmo que a pessoa quer e pode correr;

- Antecipar o relato de obstáculos.

Fonte: Elaborado pelos autores. 
Quadro 4 - Direcionamentos práticos para a população em geral

- Abrir espaço para o corredor com deficiência visual e seu guia;

- Oferecer ajuda nas travessias;

- Oferecer ajuda para pegar ônibus;

- Não estacionar carro em cima das calçadas;

- Não colocar carrinhos de supermercado nas calçadas;

- Respeitar as regras impostas pelas organizadoras de provas de rua.

Fonte: Elaborado pelos autores.

\section{REFERÊNCIAS}

ABNT. NBR 14022: Acessibilidade em veículos de características urbanas para o transporte coletivo de passageiros. Rio de Janeiro: ABNT, 2011. Disponível em: https:/www.cnmp.mp.br/portal/images/ Comissoes/DireitosFundamentais/Acessibilidade/NBR_14022-2011_Onibus_Ed4.pdf. Acesso em: 8 nov. 2019.

ALVES, Maria Luíza Tanure; DUARTE, Edison. A inclusão do deficiente visual nas aulas de educação física escolar: impedimentos e oportunidades. Acta Scientiarum. Human and Social Sciences, v. 27, n. 2, p. 231-237, 2005.

BARDIN, Laurence. Análise de conteúdo. Ed. rev. atual. Lisboa: Edições, v.70, 2009.

BRAGA, Juliana Cristina; CAMPI JUNIOR, Antônio Carlos Costa; DAMACENO, Rafael Jeferson Pezzuto; ALBERNAZ, Neno Henrique da Cunha. Estudo e relato sobre a utilização da tecnologia pelos deficientes visuais. Cuiabá, 2012. Disponível em: https://www.researchgate. net/publication/262243467 Estudo e relato sobre a utilizacao da tecnologia pelos deficientes visuais. Acesso em: 8 nov. 2018.

BRASIL. Lei no 13.146, de 6 de julho de 2015. Institui a Lei Brasileira de Inclusão da Pessoa com Deficiência. Disponível em: http://www.planalto.gov.br/ccivil 03/ ato2015-2018/2015/lei/l13146.htm. Acesso em: 16 maio 2019.

BRASIL. Câmara dos Deputados. Projeto de lei n.․ 6.860, DE 2017. Disponível em: http://www.camara. gov.br/proposicoesWeb/prop_mostrarintegra;jsessionid=F9CDD9DDA7AE686D7ABC7F91A5D6EEF0.pr oposicoesWebExterno1?codteor=1527487\&filename=Avulso+-PL+6860/2017. Acesso em: 4 nov.2019.

CAREGNATO, Rita Catalina Aquino; MUTTI, Regina. Pesquisa qualitativa: Análise de discurso versus análise de conteúdo. Revista Texto \& Contexto Enfermagem, v. 15, n. 4, p.679-684, 2006.

CERVANTES, Carlos Roberto Macías; PORRETTA, David. Physical activity measurement among individuals with disabilities: a literature review. Adapted Physical Activity Quarterly, v. 27, p.173190, 2010.

CORDEIRO, Patrícia Da Assunção Calhabrêz. Atividade Física e o Bem-Estar para Pessoas

Cegas. 2016. 85f. Dissertação (Mestrado - Educação Física), Universidade de Trás - os Montes e Alto Douro, Vila Real, 2016.

CPB - Comitê Paralímpico Brasileiro. Normas para participação de atletas com deficiência em corridas de rua. [2019]. Disponível em: http://www.cbat.org.br/repositorio/cbat/documentos oficiais/ normas oficiais/norma07 anex02.pdf. Acesso em: 7 nov. 2018. 
CURITIBA (PR). Curitiba implanta semáforos especiais para pessoas com mobilidade reduzida. Curitiba, 2015. Disponível em: http://www.curitiba.pr.gov.br/noticias/curitiba-implanta-semaforosespeciais-para-pessoas-com-mobilidade-reduzida/36127. Acesso em: 3 nov. 2019.

CURITIBA (PR). Curso forma guias para atletas com deficiência visual. Curitiba, 2013. Disponível em: http://www.curitiba.pr.gov.br/noticias/curso-forma-guias-para-atletas-com-deficiencia-visual/31624. Acesso em: 3 nov. 2019.

FLORIANÓPOLIS (SC). Lei complementar n. 482, de 17 de janeiro de 2014.

Disponível em: http://www.pmf.sc.gov.br/arquivos/arquivos/pdf/04 022014 12.01.39. ae8afdb369c91e13ca6efcc14b25e055.pdf. Acesso em: 3 nov. 2019.

GREGUOL, Márcia. Atividades físicas e esportivas e pessoas com deficiência. Relatório de Desenvolvimento Humano Nacional - Movimento é vida: Atividades físicas e esportivas para todas as pessooas. Brasília: PNUD, 2017.

IBGE- Instituto Brasileiro de Geografia e Estatísticas. Cartilha do Censo 2010: Pessoas com deficiência. Brasília: Secretaria Nacional de Promoção dos Direitos da Pessoa com Deficiência (SNPD), 2012.

IBGE- Instituto Brasileiro de Geografia e Estatísticas. Pesquisa Nacional de Saúde 2013: Ciclos de vida: Brasil e grandes regiões. Rio de Janeiro: IBGE, 2015.

JAARSMA, Eva; DEKKER, Rienk; KOOPMANS, Steven; DIJKSTRA, Pieter; GEERTZEN, Jan. Barriers and facilitators of sports participation in people with visual impairments. Adapted Physical Activity Quarterly, v. 31, n. 3, p. 240-264, 2014.

JESUS, Gilmar Mercês de; JESUS, Éric Fernando Almeida de. Nível de atividade física e barreiras percebidas para a prática de atividades físicas entre policiais militares. Revista Brasileira de Ciências do Esporte, v. 34, n. 2, p. 433 - 448, 2012.

KIRCHNER, Corinne; GERBER, Elaine; SMITH, Brooke. Designed to deter: community barriers to physical activity for people with visual or motor impairments. American journal of preventive medicine, v. 34, n. 4, p. 349-352, 2008.

LIMA, Carlos Roberto Ferraz de; GORGATTI, Márcia Greguol; DUTRA, Milena Carrijo. A influência do esporte na qualidade de vida das pessoas com deficiência visual. Revista Brasileira de Ciências da Saúde, v. 8, n. 23, p. 40-47, 2010.

NEWTON, Paulla Christianne Da Costa; ARAÚJO, Ludmila Albuquerque Douettes. Vulnerabilidade e espaço urbano: Medidas para a desconstituição dos obstáculos urbanos no cerne da lei n.13.146, de 6 de julho de 2015, de inclusão da pessoa com deficiência. Revista de Direito Urbanístico, Cidade e Alteridade, Brasília, v. 2, n. 1, p.137-157, 2016.

PONTE, Aline Sarturi; SILVA, Lucielem Chequim da. A acessibilidade atitudinal e a percepção das pessoas com e sem deficiência. Cadernos Brasileiros de Terapia Ocupacional, v. 23, n. 2, p. 261 $271,2015$.

RANGEL, Gabriel Mamoru Masuda; FARIAS, Joni Márcio de. Incidência de lesões em praticantes de corrida de rua do município de criciúma, Brasil. Revista Brasileira de Medicina do Esporte, v. 22, n. 6, p. 496-500, 2016.

REINALDI, Letícia Ramos; CAMARGO JÚNIOR, Cláudio Rosa de; CALAZANS, Angélica Toffano Seidel. Acessibilidade para pessoas com deficiência visual como fator de inclusão digital. Universitas: 
RELATÓRIO Mundial sobre a Deficiência. São Paulo: SEDPcD, 2012. 334 p.

SCELZA, William; KALPAKJIAN, Claire Zabelle; ZEMPER, Eric; TATE, Denise Galuf. Perceived barriers to exercise in people with spinal cord injury. American Journal Physical Medicine \&

Rehabilitation, v. 84, n. 8, p. 576-583, 2005.

SERON, Bruna Barboza; ARRUDA, Gustavo Aires de; GREGUOL, Márcia. Facilitadores e barreiras percebidas para a prática de atividade física por pessoas com deficiência motora. Revista Brasileira de Ciências do Esporte, v. 37, n. 3, p. 214-221, 2015.

SHIELDS, Nora; SYNNOT, Anneliese Jane; BARR, Megan. Perceived barriers and facilitators to physical activity for children with disability: a systematic review. British Journal of Sports Medicine, v. 46, n. 14, p. 989-997, 2012.

SOUZA, Paulo Cordeiro de; BRUEL, Maria Rita. Atletismo para deficiente visual. Revista Ágora, v. 16, n. 2, p. 409-413, 2012. 